\title{
Gambaran Peningkatan Lingkup Gerak Sendi Setelah Pemberian Range of Motion Pada Pasien Stroke : Literature Review
}

\author{
Ahmad Sofyan $1 *$, Nurul Aktifah ${ }^{2}$ \\ ${ }^{1,2}$ Proram Studi Sarjana Fisioterapi Universitas Muhammadiyah Pekajangan Pekalongan Jln. \\ Raya Ambokembang No. 8 Kedungwuni Pekalongan Indonesia \\ *email: AhmadShofyan@gmail.com
}

\begin{abstract}
Abstrack
Stroke is a brain functional disorder that occurs suddenly with clinical signs and symptoms both focal and global that lasts more than 024 hours the event will cause permanent damage to the brain. In stroke patients, the role of physiotherapists is to restore the functional range of motion of the joints, one of which is by administering Range Of Motion (ROM) which aims to increase the range of motion of the joints. The purpose of this study is to describe the description of the increase in the range of motion of the joints after the provision of range of motion (ROM) in stroke patients. Methods: The selection of articles in this study used the PICO mnemonic. Writing articles using a literature review search from the Garuda/Scholer Portal and NCBI). The results of a literature review review of 5 articles showed that there was an increase in joint range of motion in stroke patients with an average of 60.322 before intervention and 66.42 after intervention. . Range of motion is able to increase the range of motion of joints in stroke patients. Suggestion: It is hoped that it will provide input in alternative methods of physiotherapists in providing Range of motion in order to increase the range of joint motion in stroke patients.
\end{abstract}

Keywords: Range Of Motion, Scope of joint motion; stroke

\begin{abstract}
Abstrak
Stroke merupakan suatu gangguan fungsional otak yang terjadi secara mendadak dengan tanda dan gejala klinik baik fokal maupun global yang berlangsung lebih dari 24 jam kejadian tersebut akan menimbulkan kerusakan permanen pada otak. Pasien stroke Peran fisioterapis untuk mengembalikan fungsional lingkup gerak sendi salah satunya dengan melakukan pemberian Range of Motion (ROM) yang bertujuan untuk meningkatkan lingkup gerak sendi. Tujuan penelitian ini yaitu mendeskripsikan Gambaran Peningkatan Lingkup gerak sendi Setelah Pemberian Range Of Motion (ROM) Pada Pasien Stroke .Pemilihan artikel pada penelitian ini menggunakan mnemonic PICO. Penulisan artikel menggunakan penelusuran literature review dari Portal Garuda/Scholer dan NCBI). Hasil literature review review 5 artikel menunjukkan bahwa Adanya peningkatan kemampuan lingkup gerak sendi pada pasien stroke dengan rata rata sebelum intervensi sebesar 60,322 dan sesudah intervensi sebesar 66,42 Range of motion mampu untuk meningkatkan lingkup gerak sendi pada pasien stroke. Penelitian ini menerangkan tentang metode alternative fisioterapis dalam pemberian Range of motion guna meningkatkan lingkup gerak sendi pada pasien stroke.
\end{abstract}

Kata Kunci: Range OfMottion, Lingkup gerak sendi ; Stroke 


\section{Prosiding Seminar Nasional Kesehatan Lembaga Penelitian dan Pengabdian Masyarakat Universitas Muhammadiyah Pekajangan Pekalongan

\section{Pendahuluan}

Penyakit tidak menular (PTM) merupakan penyebab kematian di dunia dengan jumlah kematian sebesar 36 juta jiwa setiap tahunnya (World Health Organization, 2010). Data word stroke organization menunjuukan 13,7 juta kasus kematian terjadi karena stroke. Sekitar $70 \%$ penyakit stroke $87 \%$ nya mengalmai kematian. Pada tahun 2020 didapatkan prevalensi mengalami stroke sebanyak 2.565.601. Data Riset Kesehatan Dasar (RISKESDAS) tahun 2020 prevalensi stroke di Indonesia sebesar 10,9 $\%$. Prevalensi stroke berdasarkan diagnosis dokter pada penduduk umur $\geq 15$ tahun yang tertinggi terdapat di Provinsi Kalimantan Timur (14,7 \%), di Provinsi Papua menjadi provinsi dengan tingkat pravelensi stroke paling rendah $(4,1 \%)$ per mil sedangkan di Jawa Tengah menempati urutan ke sebelas. Angka kejadian stroke di Indonesia setiap tahunnya sekitar 500.000 jiwa serta sekitar 125.000 atau 25\% jiwa meninggal dunia akibat stroke sedangkan sisanya mengalami cacat ringan hingga berat (Parida, 2018). Data yang diperoleh dari Dinas Kesehatan (Dinkes) Kabupaten Pekalongan menunjukkan bahwa di Kabupaten Pekalongan pada tahun 2019 terdapat 866 (46\%) kasus stroke (Dinkes Kabupaten Pekalongan, 2019).

Gangguan pembuluh darah otak atau stroke termasuk salah satu penyakit tidak menular yang sering ditemukan. Stroke adalah penyakit neuro yang disebabkan oleh terganggunya suplai darah ke bagian otak (Black, 2014). Pola hidup tidak sehat, gangguan pola makan, kurangnya olahraga, aktivitas maupun jam kerja yang berlebihan akan beresiko untuk mengalami serangan stroke (Irfan, 2012, h.59). Sel-sel saraf yang mengalami iskemik, 80\% Cerebral blood flow (CBF) $10 \mathrm{ml} / 100 \mathrm{gr}$ jaringan otak/menit) akan mengalami kerusakan irreversible dalam beberapa menit yang mengakibatkan Pasien pasca stoke menjadikan kelemahan pada salah satu sisi tubuhnya. Kelemahan tangan maupun kaki pada pasien stroke akan memgambarani rentan gerak sendi. Berkurangnya rentan gerak sendi disebabkan karena kurangnya suplai darah ke otak belakang dan otak tengah, sehingga dapat menghambat hantaran jaras-jaras utama antara otak dan medula spinalis serta adanya kelemahan dan kelumpuhan pada tangan maupun kaki merupakan dampak stroke pada fisik. Sebesar 30-40\% penderita stroke dapat sembuh sempurna bila dapat ditangani dalam waktu 6 jam pertama (Golden Periode), namun apabila dalam waktu tersebut tidak mendapatkan penanganan yang maksimal maka akan terjadi kecacatan atau kelemahan fisik (Nabyl 2012).

Lingkup gerak sendi merupakan Gerak penuh yang dapat dilakukan disebut lingkup gerak sendi. Istilah seperti fleksi, ekstensi, abduksi, adduksi, dan rotasi dapat digunakan untuk menjelaskan lingkup gerak sendi Hilangnya atau menurunnya lingkup gerak sendi secara aktif maupun pasif yang disebabkan oleh keterbatasan sendi, fibrosis jaringan penyokong, otot serta kulit. Paralisis (kelumpuhan) merupakan termasuk salah satu gejala klinis pada kasus stroke. Gangguan peredaran darah ke otak menimbulkan gangguan pada metabolisme sel neuron dan sel otak karena akan menghambat mitokondria dalam menghasilkan Adenosine Triphosphate (ATP), sehingga terjadi gangguan fungsi seluler dan aktivasi berbagai proses toksik. 


\section{Prosiding Seminar Nasional Kesehatan \\ Lembaga Penelitian dan Pengabdian Masyarakat Universitas Muhammadiyah Pekajangan Pekalongan}

Penanganan pasien stroke proses rehabilitasi merupakan proses yang sangat penting dalam mengembalikan dan memperbaiki anggota gerak tubuh yang mengalami gangguan. Pada kondisi ini pasien yang mengalami rehabilitasi akan stabil serta masuk dalam proses pemulihan, Penderita stroke membutuhkan waktu yang lama untuk memulihkan dan memperoleh fungsi penyesuaian diri secara maksimal. Terapi dibutuhkan segera untuk mengurangi cidera cerebral lanjut, salah satu progam rehabilitas yang dapat diberikan untuk memperbaiki lingkup gerak sendi pasien (Sardjito, 2019).

Latihan Range Of Motion ( $R O M$ ) adalah salah satu bentuk latihan dalam proses penyembuhan pada pasien stroke. Pelatihan Range Of Motion termasuk salah satu bentuk rehabilitasi awal pada pasien stroke yang dapat dilakukan. Jenis latihan yang dapat digunakan untuk meningkatkan lingkup gerak sendi diataranya pasif rom, aktif rom aktif-asistif rom (Kisner \& Colby, 2017. h. 54). Beberapa penelitian menyatakan latihan pasif rom dapat dilakukan untuk meningkatkan lingkup gerak sendi yang mengalami paralisis (kelumpuhan) pada pasien stroke, sehingga peneliti tertarik untuk mereview "Gambaran Range Of Motion. Terhadap Lingkup gerak sendi Pada Pasien Stroke"

\section{Metode}

\section{Pemilihan Artikel}

Pemilihan artikel pada penelitian ini menggunakan PICO, dengan penjelasan sebagai berikut:

1. $\mathrm{P}$ (Population)

Pasien stroke yang mengalami penurunan lingkup gerak sendi

2. I (Intervention)

Range Of Motion

3. C (Comparative Intervention)

Dalam penelitian ini tidak ada pembanding

4. O (Outcome)

Peningkatan lingkup gerak sendi

\section{Seleksi Studi}

Kriteria inklusi meliputi sesuai dengan kata kunci, artikel yang dipublikasikan dalam rentang tahun 2010-2020, menggunakan Bahasa Indonesia maupun Bahasa Inggris, Kriteria inklusi Patiens stroke, Kriteria eksklusi Jurnal Sistematic Review, Literature Review

\section{Hasil Dan Pembahasan}

\section{Hasil}

Hasil penelusuran literature lima artikel dengan pemilihan sesuai kriteria inklusi dan ekslusi. Artikel yang direview menghasilkan data berupa karakteristik responden serta hasil pengaruh pre test dan post test.serta pengaruh Range Of Motion Terhadap Lingkup gerak sendi Pada Pasien Stroke 


\section{Lembaga Penelitian dan Pengabdian Masyarakat} Universitas Muhammadiyah Pekajangan Pekalongan

1. Karakteristik Responden

Hasil analisis 5 artikel didapatkan responden sebanyak 74 responden. Karakteristik jenis kelamin didapatkan sejumlah 74 responden, dari 5 artikel mencantumkan karakteristik jenis kelamin.

Hasil analisa karakteristik responden disajikan dalam tabel 4.1 sebagai berikut: Tabel 3.1 Hasil Analisis Literature Review Berdasarkan Karakteristik Responden

\begin{tabular}{|c|c|c|c|c|c|c|c|}
\hline \multicolumn{3}{|c|}{ Artikel } & \multicolumn{5}{|c|}{ Karakteristik Subjek } \\
\hline & Tahun & & \multicolumn{2}{|c|}{ Jenis Kelamin } & \multicolumn{3}{|c|}{ Umur } \\
\hline Penulis & Penelitian & Tempat & Laki-Laki & Perempuan & & Tahun & \\
\hline $\begin{array}{l}\text { Prasadhana et } \\
\text { al (2015) }\end{array}$ & 2015 & Indonesia & $17(77,3 \%)$ & $5(22,7 \%)$ & $\begin{array}{c}46-55 \\
\text { tahun }=7 \\
(31,8 \%)\end{array}$ & $\begin{array}{c}56-65 \\
\text { tahun }=10 \\
(45,5 \%)\end{array}$ & $\begin{array}{c}>65 \text { tahun }=5 \\
(22,7 \%)\end{array}$ \\
\hline $\begin{array}{l}\text { Jin Lee, et al } \\
(2017)\end{array}$ & 2017 & Korea & $8(47 \%)$ & $9(53 \%)$ & & $\begin{array}{c} \pm 58 \text { tahun }= \\
17(100)\end{array}$ & \\
\hline $\begin{array}{l}\text { Elisa Ling } \\
\text { Dinanti et al } \\
(2015)\end{array}$ & 2015 & Indonesia & $18(81,8 \%)$ & $4(18,2 \%)$ & & $\begin{array}{c}46-55 \\
\text { tahun }=5 \\
(22,7 \%)\end{array}$ & $\begin{array}{l}56-65 \text { tahun } \\
=17(77,3 \%)\end{array}$ \\
\hline $\begin{array}{l}\text { Suarti dan } \\
\text { Rohani (2017) }\end{array}$ & 2017 & Indonesia & $16(53 \%)$ & $14(47 \%)$ & NM & NM & NM \\
\hline \multirow[t]{2}{*}{$\begin{array}{l}\text { Murtaqib } \\
(2013)\end{array}$} & 2019 & Indonesia & NM & NM & NM & NM & NM \\
\hline & & & $59(64,8 \%)$ & $32(35,2 \%)$ & & $40-60$ tahur & \\
\hline
\end{tabular}

(NM = Not mention in article)

Hasil analisis menyatakan bahwa jenis kelamin laki-laki lebih banyak dibandingkan perempuan, pada karakteristik subjek jenis kelamin laki-laki sebesar $64,9 \%$ dan perempuan $35,1 \%$. Karakteristik Subjek umur terdapat pada 5 artikel didapatkan hasil 6 responden $(6,7)$ berusia $<40$ tahun, 43 responden $(48,3 \%) 40$ -60 tahun dan 25 responden $(28 \%)>60$ tahun

2. Gambaran Lingkup gerak sendi dengan intervensi ROM

Lingkup gerak sendi dengan pada pasien stroke dengan intervensi ROM pada 5 artikel dapat dilihat pada tabel 4.2

Tabel 3.2 Hasil Analisis Literature Review Peningkatan Lingkup gerak sendi dengan Intervensi ROM $(N=74)$

\begin{tabular}{|c|c|c|c|c|c|c|c|}
\hline \multirow[t]{2}{*}{ No } & \multicolumn{3}{|c|}{ Artikel Tahun } & \multicolumn{3}{|c|}{ Karakteristik Responden } & \multirow[b]{2}{*}{$P$ value } \\
\hline & Penulis & Tahun & Tempat & Dosis & Pre Test & Post Test & \\
\hline 1 & $\begin{array}{l}\text { Prasadhana et } \\
\text { al (2015) }\end{array}$ & 2015 & Indonesia & 1x/hari, selama 7 hari. & 151,36 & 149,82 & 0,000 \\
\hline 2 & $\operatorname{lin}_{(2017)}$ Lee, et al & 2017 & Korea & $\begin{array}{c}5 \times / \text { minggu selama } 4 \\
\text { minggu }\end{array}$ & 14,1 & 17,1 & 0,000 \\
\hline 3 & $\begin{array}{l}\text { Elisa } \\
\text { Dinanti et al } \\
(2015)\end{array}$ & 2015 & Indonesia & 1x/hari, selama 7 hari. & 7,95 & 24,31 & 0,001 \\
\hline 4 & $\begin{array}{l}\text { Suarti dan } \\
\text { Rohani (2017) }\end{array}$ & 2017 & Indonesia & $\begin{array}{c}\text { 2x/hari } \\
\text { selama íz } \\
\text { hari. }\end{array}$ & 66 & 84,3 & 0,000 \\
\hline \multirow[t]{2}{*}{5} & $\begin{array}{l}\text { Murtaqib } \\
(2013)\end{array}$ & 2013 & Indonesia & $\begin{array}{l}\text { 1-3x/hari } \\
\text { dengan sela- } \\
\text { ma } 7 \text { hari }\end{array}$ & 125,27 & 136,67 & 0,001 \\
\hline & & & & & 72,93 & 82,44 & 0,000 \\
\hline
\end{tabular}




\section{Prosiding Seminar Nasional Kesehatan \\ Lembaga Penelitian dan Pengabdian Masyarakat Universitas Muhammadiyah Pekajangan Pekalongan}

Hasil literature review analisis dari 5 artikel didapatkan bahwa terdapat didapatkan lingkup gerak sendi dengan intervensi ROM memiliki rata - rata sebelum intervensi sebesar 72,93 dan sesudah intervensi sebesar 82,44.

\section{Pembahasan}

\section{Karakteristik Responden}

Hasil literature review didapatkan karakteristik jenis kelamin responden paling banyak adalah laki-laki sebesar $59(64,8 \%)$ responden, pada karakteristik usia responden paling banyak adalah usia 40-65 tahun.

Hasil penelitian didapatkan responden yang karakteristik jenis kelamin lakilaki. Laki-laki lebih beresiko mengalami stroke sedangkan perempuan lebih cenderung mengalami stroke haemoragik (Nably, R.A 2012). Karena pada wanita terdapat hormon estrogen yang dapat menjaga pembuluh darah di otak tetap sehat dengan meningkatkan efesiensi mitokondria dalam pembuluh darah di otak, sehingga resiko tertinggi stroke lebih banyak terjadi pada laki-laki (Dandayani, 2018). Penyebab lain stroke karena pola hidup dan gaya hidup yang banyak ditemukan pada laki-laki yang memiliki kebiasaan merokok yang menyebabkan penyumbatan di pembuluh darah (Hamra, 2015).

Hal ini sesuai dengan penelitian havid (2012) yang menyatakan bahwa lakilaki beresiko terkena stroke dibandingkan perempuan. Jenis kelamin mempengaruhi dalam peningkatan lingkup gerak sendi. Perempuan memiliki rentang gerak sendi yang lebih besar daripada laki-laki, hal tersebut disebabkan ligamen pada perempuan lebih lentur dan massa otot lebih kecil. Pada usia yang sama, perempuan lebih fleksibel dibandingkan laki-laki (Murtaqib, 2013).

Karakteristik usia didapatkan hasil usia responden paling banyak pada usia 4065 tahun. Stroke biasa menyerang pada usia diatas 40 tahun, namun dengan jenis makanan yang ada saat ini menutup kemungkinan stroke dapat menyerang seseorang pada usia muda (Nably, 2012). Usia responden juga mempengaruhi hasil lingkup gerak sendi. Seiring dengan bertambahnya usia terdapat perubahan pada sistem muskuloskeletal dimana terjadi penurunan fungsi, massa otot berkurang, energi berkurang, gangguan pada sendi kartilago dan tulang yang mulai rapuh sehingga dapat mempengaruhi kemampuan saat melakukan latihan pasif range of motion. Usia diatas 55 tahun, resiko terkena stroke akan bertambah dua kali lipat setiap kurun waktu sepuluh tahun (Anita, 2018).

Hal ini sesuai dengan penelitian claudia (2013) stroke dapat terjadi pada segala jenis usia dan kejadian stroke meningkat setiap pertambahan sejak usia 40 tahun keatas. Faktor yang berpengaruh terhadap terjadinya stroke pada usia muda dibawah 40 tahun dengan riwayat hipertensi, kolestrol dan riwaayat stroke pada keluarga.

\section{Gambaran Lingkup gerak sendi}

Hasil literature review pada 5 artikel didapatkan rata-rata dosis latihan ROM 1 xdalam 1 hari, selama 7 hari. Hasil lingkup gerak sendi lingkup gerak sendi 


\section{Prosiding Seminar Nasional Kesehatan Lembaga Penelitian dan Pengabdian Masyarakat Universitas Muhammadiyah Pekajangan Pekalongan

paling tinggi didapatkan pada penelitian Elisa Ling Dinanti et al (2015) dan Suarti dan Rohani (2017)

Hasil literature review didapatkan nilai $\mathrm{p}<\alpha$, dimana nilai $\alpha 0,05$. Hasil tersebut menunjukkan bahwa terdapat pengaruh latihan (ROM) memiliki pengaruh dalam lingkup gerak sendi pada pasien stroke. Menurut Anita (2018) pasien stroke seringkali mengalami kelemahan pada satu sisi anggota tubuh atau hemiparese yang mengakibatkan penurunan tonus otot sehingga terjadi imobilisasi. Imobilisasi dapat menimbulkan komplikasi seperti kontraktur atau penurunan lingkup gerak sendi. Berdasarkan hasil literature review didapatkan bahwa lingkup gerak sendi ekstremitas atas pada 148 responden mengalami keterbatasan gerak.

Stroke merupakan kondisi darurat dimana keadaan pasien stroke yang sudah membaik atau dalam keadaan stabil (Samiadi, 2019, h.1). Rehabilitasi pada stroke paling tepat dilakukan 24-48 jam setelah serangan stroke dengan catatan bahwa kondisi pasien sudah stabil (Adrian, 2018). Stroke subakut berlangsung mulai dari 2 minggu sampai 6 bulan stroke serta merupakan fase yang penting untuk dilakukan pemulihan fungsional (golden period). Pada fase ini kondisi medis dan hemodinamik telah stabil serta adanya proses pemulihan, reorganisasi pada sistem saraf sehingga dapat mengoptimalkan pemulihan setelah stroke (Sardjito, 2019).

Latihan Pasif range of motion merupakan latihan gerak sendi yang memungkinkan terjadinya kontraksi dan pergerakan otot serta dilakukan dengan adanya bantuan dari luar (Nugroho, 2016). Hasil penelitian yang dilakukan oleh Anita, Pongantung, Ada, Hingkam (2018) menyatakan bahwa latihan pasif range of motion berpengaruh untuk meningkatkan lingkup gerak sendi.

Hasil penelitian tersebut sejalan dengan Hasil penelitian yang dilakukan Elisa Ling Dinanti et al (2015) menyatakan bahwa latihan Range of motion (ROM) efektif untuk meningkatkan lingkup gerak sendi pada pasien stroke. Hal ini sejalan dengan penelitian Suarti dan Rohani (2017) . Beberapa penelitian tersebut menyatakan bahwa latihan Range of motion (ROM) efektif untuk meningkatkan kemampuan lingkup gerak sendi pada pasien stroke.

\section{Simpulan Dan Saran}

\section{Simpulan}

Simpulan dari analisis literature review tersebut adalah Jenis kelamin responden yang paling banyak adalah laki-laki sebesar $64,8 \%$, sedangkan karakteristik usia responden yang paling banyak adalah usia 40-65 tahun. Adanya peningkatan kemampuan lingkup gerak sendi pada pasien stroke dengan rata - rata sebelum intervensi sebesar 72,93 dan sesudah intervensi sebesar 82,44.

\section{Saran}

Melalui penelitian ini diharapkan dapat memberikan informasi dan konstribusi terkait dengan latihan range of motion untuk meningkatkan lingkup gerak sendi pada pasien stroke bagi mahasiswa Universitas Muhammadiyah Pekajangan Pekalongan serta menambah kepustakaan dan bahan referensi bagi tenaga kesehatan dan 


\section{Prosiding Seminar Nasional Kesehatan Lembaga Penelitian dan Pengabdian Masyarakat Universitas Muhammadiyah Pekajangan Pekalongan

dijadikan sebagai intervensi mandiri yang dapat dilakukan untuk meningkatkan lingkup gerak sendi pasien stroke serta menambah pengetahuan mengenai penyakit stroke dan lgerak sendi pada pasien stroke dengan memberikan intervensi range of motion.

\section{Referensi}

Anita, F, Pongatung, H, Veni Ada, P \& Hingkam, V. (2018). Gambaran Latihan Range Of Motion Terhadap Rentang Gerak Sendi Ekstremitas Atas Pada Pasien Stroke Di Makasar. Makasar. Journal Of Islamic Nursing. Vol 3 (1).

Ahmad, A, Aras, D, Ahmad, H. (2016). The New Concept Of Physical Therapist Test And Measurement. Edisi Pertama. Makasar: Physiocare Publishing.

Bakara, D, M, Warsito, S. (2016). Latihan Range Of Motion Pasif terhadap rentang sendi pasien stroke. Rejang Lebong: Idea Nursing Journal.

Bickley, L. S. (2013). Buku Ajar Pemeriksaan Fisik \& Riwayat Kesehatan. Edisi Kesebelas. Jakarta: EGC.

Damayanti, S, Fitriana, L, B, Judha, M, Nekada, Wahyuningsih, M. (2017). Sistem Muskuloskeletal dan Integumen. Yogyakarta: Nuha Medika

Dinanti, E. L, Hartono, M, Wulandari. (2015). Gambaran Range Of Motion (ROM) Pasif Terhadap Peningkatan Sudut Rentang Gerak Ekstremitas Atas

Pasien Stroke Di RSUD Tugurejo Semarang. Semarang. Jurnal Ilmu Keperawatan dan Kebidanan.

Dinas Kesehatan Kabupaten Pekalongan (2019). „Laporan Penyakit Tidak Menular, Data Dinas Kesehatan Kabupaten Pekalongan.

Djikstra, P, U, De Jong, L, D, Postema, K, Stewart, R, E. (2012). Repeated measurements of arm joint passive Range Of Motion after stroke: interobserver reliability and sources of variation. Amerika Utara: American Physical Therapy Association.

Hernata, I. (2013). Ilmu Kedokteran Lengkap Tentang Neurosains. Edisi Pertama. Jogjakarta: D-Medika.

Irfan, M. (2012). Fisioterapi bagi Insan Stroke. Edisi Kedua. Yogyakarta: Graha Ilmu.

Kisner, C \& Colby, L. A. (2017). Terapi Latihan Dasar Dan Teknik Therapeutic Exercise : Fundations and Techniques. F. A. Davis Company, USA. 1 (6).

La Ode, S. (2017). Asuhan Keperawatan Gerontik Berstandarkan Nanda, NIC, dan NOC Dilengkapi Teori dan Contoh Kasus Askep. Cetakan Kedua. Y Yogyakarta: Nuha Medika.

Lee, Y, Kim, H, J, Sohng, K, Y. (2014). Effects of bilateral Range Of Motion exercise on the function of upper extremities and activities of daily living in patients with acute stroke. Korea Selatan: The Society OF Physical Therapy Science.

Nabyl, R.A. (2012). Deteksi Dini Gejala \& Pengobatan Stroke. Yogyakarta:Aulia Publishing. 


\section{Prosiding Seminar Nasional Kesehatan Lembaga Penelitian dan Pengabdian Masyarakat Universitas Muhammadiyah Pekajangan Pekalongan}

Nugroho, A. (2016). Gambaran Latihan Range Of Motion (ROM) Pasif Terhadap Lingk gerak sendi Pada Pasien Stroke Non Hemoragik Di Ruang ICU RSUD Kabupaten Karanganyar. Karanganyar. Jurnal Ilmu Keperawatan.

Permadi, A.W. (2019). Fisioterapi Manajemen Komprehensif Praklinik. Jakarta: EGC.

Pinzon, R \& Asanti, L. (2010). Awas Stroke! Pengertian, Gejala, Tindakan \& Pencegahan. Edisi Pertama. Yogyakarta: CV. Andi Offset.

Samiadi Lika Aprilia 2019.2 HelloS ehat, https://googleweblight.com/1?u=https://hellosehat.com/pusatkesehatan/st ke-2/apa-yang terjadi-pada-tubuh-setelah-stroke-berlalu\&hl=id-ID.

Sardjito. (2019). Tingkatkan Kualitas Hidup Pasien Stroke Dengan Layanan Neuro Restorasi. https://sardjito.co.id/2019/05/27/tingkatkan-kualitas hiduppasien-stroke-dengan-layanan-neuro-restorasi/. (22 Mei 2019).

Sherwood L. 2012. Fisiologi manusia dari sel ke sistem. 6th ed. Jakarta: EGC;

Tilong, A, D. (2012). Kitab Herbal Khusus Terapi Stroke. Edisi Pertama. Jogjakarta: D-Medika. 